\title{
THE DRAMATIST AND CRIME MANAGEMENT FOR NATIONAL STABILITY: AN ANALYSIS OF TRACIE UTOH'S THE NIGHT OF A THOUSAND TRUTHS
}

\author{
Aondowase Boh \\ Benue State University, Makurdi \\ *http://dx.doi.org/10.4314/ujah.v14i3.7
}

\section{Abstract}

Dramatists have used their dramatic ingenuity to comment on political, social, economic and security challenges in their societies over the years. The dramatists do this in order to chart the way forward for a stable political, economic and social system. It is in this wise that, Tracie Utoh-Ezeajuh has used her knowledge of drama to comment on serious issues bedevilling the progress and stability of the nation. The security challenges bedevilling the nation are linked to the fragile family system and what happened as regards the children's upbringing by their respective families. This paper analyses one of Utoh's plays, The Night of a Thousand Truths with a view to educating Nigerian families on what is expected of them as far as the issue of national security and social stability is concerned. This is done with the realisation that the family is the first unit of socialisation. The proper socialisation of children by their parent is therefore a stepping stone for national security and social stability.

\section{Introduction}

It is generally agreed that some of the major determinants of delinquent behaviours lie in the social environment in factors such as poverty, lack of education, broken homes and demoralise neighbourhoods. Any hope that criminals might somehow turn out to be different by nature from the rest of us, 
and that we might thus be relieved of the responsibility for changing the environmental conditions which promote delinquency and criminality has been repeatedly disappointed. The life of crime is as stated above associated with some fundamental family conditions. Crime itself is looked upon as: An action or omission that constitute an offence that may be prosecuted by the state and is punishable by the law of the nation or by the people.

There are two main categories of crime. There is property crime and violent crime. Property crime occurs when someone damages, destroys or steals some one's property. When someone steals a car or vandalise a building he/she is said to have committed property crime. Violent crime on the other hand occurs when someone harms, attempts to harm, threatens to harm or even conspires to harm someone else. Violent crimes are offences which involve force or threat of force such as rape, robbery or homicide. Some crimes can be property and violent crimes at the same time. Carjacking someone's vehicle at gun point or robbing a shop owner with a hand gun is an example of such crimes.

Some crimes can involve no action at all but rather not taking action. Withholding medication or neglecting someone who needs medical care or attention can be considered a crime. If for instance you know someone who is abusing a child and you do not report it under some circumstance you could be charge with crime for failing to act. Criminality according to Sanford Nevitt is "a set of attitudes towards conscience and society. It is something that exists within the individuals, though it commonly leads to offences against the legal code ..." (117). The family plays a central role in ensuring the effective continuity of the society. The family characteristics that are associated with delinquency are parental criminality, 
The Dramatist and Crime Management for National Stability: An Analysis of Tracie Utoh's The Night of a Thousand Truths - Aondowase Boh, PhD

ineffective supervision and discipline, familial discord and disharmony, weak parent-child relationship, large family size, and psycho social disadvantage.

Drama has over the years been used to comment on social political and economic conditions in the society with a view to correcting societal ills for the progress and development of the society. Dramatists have portrayed these societal issues through action for information and education of man. Christensen and Feinberg agree with the above view when they inform that:

Drama is the art of make-believe. It captivates children and adults from all societies and walks of life. Makebelieve consists in part of acting out events that happened or that we imagine happening. Drama consists of representing those actions for the pleasure of others. The primary ingredients of drama are characters, represented by players; action, describe by gestures and movement; thought, implied by dialogue and action, spectacle represented by scenery and costume, and finally, audiences who respond to this complex mixture (1).

The medium of drama is used to address issues that are central to the progress and development of the society. The aim of drama is therefore to sensitize the people in order to effect positive social, economic and political changes in the society. Just like Achebe Chinua pointed out that ..."an African creative writer who tries to avoid the big social and political issues of contemporary Africa will end up being completely irrelevant- like that absurd man in the proverb who leaves his burning house to pursue a rat fleeing from the flames" (113). It is with this conviction that, Tracie Utoh does not want to keep 
mute about the issues of crime and criminality, a canker warm that is ravaging the progress and development of the nation. The Night of a Thousand Truths is used by the author to educate, inform and as a propaganda tool against the causes of crime and criminality especially at the family level. The playwright uses her creative dramatic ingenuity to mirror the family conditions that promote crime in the larger society and calls for arrest of such. As a watchdog of the society playwrights recreate what happens in the society with a view to pointing the way out. They therefore propagate the voice of the people. This attest to why Utoh-Ezeajugh, Tracie and Nneka Ibeli's quotation of George Thomson as quoted by Nwabueze is apt here: "The poet speaks not for himself only but for his fellow men. His cry is their cry which only he can utter. That is what gives it its depth. But if he is to speak for them he must suffer with them. Rejoice with them, work with them. Fight with them." (318-319). This gives credence to why Utoh choose to use the medium of drama to sensitise the Nigerian families against acts that will promote and encourage criminality in the society. Stella Oyedapo for instance has used the medium of drama to decry the quest for ill gotten wealth which most of the times lead people to commit serious crimes in the society. It is in a bid to trumpet the impact of drama in impacting on the issues of crime and its management that the paper attempts a critical analysis of The Night of a Thousand Truths which is an ideal drama for crime management.

\section{Theoretical Framework}

In this paper the theory that anchors the discussion of issues is social learning theory. Social learning theory's major argument is that, behaviour is learned and that crime is a product of learning. The theory offers a good explanation to the problem of crime and crime management as it relates family members. 
The Dramatist and Crime Management for National Stability: An Analysis of Tracie Utoh's The Night of a Thousand Truths - Aondowase Boh, PhD

This theory is put together by Edwin Sutherland who believed that crime was a function of learning process that could affect anyone in the society. To him acquiring behaviour is a socialisation, not a political or legal process. This notion tallies with Beirne and Messerschmidt as paraphrased by Uya that: "...skills and motives conducive to crime are learned as a result of contact with pro-crime values, attitudes and definitions and other patterns of criminal behaviour. Therefore the act of drug use and crime among the youths is socially constructed" (107108). Children basically are socialised first by their parents at the family level. The behaviour of parents to a large extent influence the attitude and thought of the children either negatively or positively. Criminal acts by the youths are learned from close associates. This means that criminal acts just like other learned behaviours are imbibed from others. Learning criminal behaviour occurs within intimate groups such as parents that indulge in it. Children that grow up in homes where their parents commit criminal acts are more likely to view such behaviours as been socially and physically beneficial. The reverse is the case for children that grow up among parents that are morally upright.

Another theory that helps explain perspective discussions of this paper is the social control theory which analyses social behaviour in a controlled society, focusing on its effects in crime reduction. It states that crime is merely the result of unsupervised anti social behaviour which can be reduced with some sort of control. In this way, society plays an important role in curbing crime. The different types of social control are: 
1. Direct control where all wrong actions receive punishments and right actions receive rewards from family or state authority.

2. Indirect control by quick identification of deviant behaviour by the family or others.

3. Internal control by the individual who tries to control deviant behaviour through the strength of his conscience.

4. Control through satisfaction. When all needs are met, the individual will not be tempted.

\section{Drama and Crime Management}

Chinua Achebe warns as quoted in Utoh- Ezeajugh and Ibeli that; "Any African writer who ignores the social and political issue of contemporary Africa will end up being completely irrelevant"(391). This means that African dramatists needed to be committed to the problems bedevilling the progress and development of African society. One of such problems is crime and criminality. Drama sets standards, practices and policies that help the society, particularly parents to manage criminal tendencies among societal members. Drama tries to reflect the reality of issues in the society. From the beginning drama has the capacity to hold up an illusion of reality like reflection in a mirror-we take the reality for granted while recognizing that it is nonetheless illusory" (The Bedford Introduction to Drama...3). Drama in this sense present community based parents' education and support systems to enhance parent's knowledge of ways that can support the development of children. Lack of family management and communication skills can make effective parenting difficult; this will in the long run affect the life of children negatively. Drama can assist parent by providing education and training in 
The Dramatist and Crime Management for National Stability: An Analysis of Tracie Utoh's The Night of a Thousand Truths - Aondowase Boh, PhD

communication skills. Through the cause of and effect of dramatic actions, families can transfer skills to their children and this will possibly prevent delinquency and the eventual life of crime.

Drama's role in crime management cannot be overemphasized. Right from the times of the Greeks (classical period) to the present, drama has played vital roles in reshaping man and his environment for the good and wellbeing of man. Crime in no way benefits man and so drama has over the years been used to trumpet the dangers associated with crime for the sake of man. The dramatists have been able to do this because, they are members of society, so naturally their artistic projections are shaped and sharpened by the socio-economic contradictions and happenings of their time. The issue of crime and criminality is obviously on the high scale in the country today this therefore gives credence to why dramatists have directed their creative arsenals to deal with the menace.

Plays are created to reflect and initiate happenings in the society that promote crime. The issue so created reflect the causes of the problems and the aftermath on individuals and the society at large. To a large extent the audience whom the plays are created for usually watch or read the said plays to help them transform their lives.

\section{The Role of the Family in Crime Management/Prevention}

The family unit is usually considered a crucial ingredient in a child's subsequent involvement in crime. From a criminological point of view, factors considered to contribute to the criminal life are: weather a child has criminal parents; the severity of discipline administered to a child; parental neglect and abuse; inadequate parental supervision; domestic 
violence; age of parents at time of child birth; parental attitudes towards violence; parental drug use; parental history of mental illness; size of the family; parent education; socioeconomic status and parental/child separation. A negative family characteristic such as poor parental supervision of children is commonly referred to as a risk factor for future delinquency or crime. Children who come from such backgrounds are believed to be at greater risk and are more likely to commit criminal offences than children who do not have such family backgrounds. The reverse is the case for a child that grows up in love, and support of home/parents. Such home/parents could be looked upon as being protective as they promote child's resilience or protective provide barriers against the onset of criminal involvement even in the light of adverse conditions.

Crime management/prevention involves any initiative or policies which help to reduce, avoid or eliminate victimization by crime or violence. It involves family members' (parents) initiatives to reduce fear of crime as well as lessen the impact of crime on victims. For crime management/prevention to be effective, parents and guardians must be ready to lead their wards by example, through such approaches like: Promoting the wellbeing of the family members (children) and encouraging pro-social behaviour through social, economic, health and educational measures with focus on reducing the risk and factors associated with crime. Change the conditions in neighbourhoods that influence offending, victimization and insecurity that results to crime. Prevent the occurrence of crimes by reducing opportunities, increasing risk of being apprehended and minimizing benefits. The onus of this rests on the dramatists to sensitise the public on this all important phenomenon. It is against this background that, dramatists over 
The Dramatist and Crime Management for National Stability: An Analysis of Tracie Utoh's The Night of a Thousand Truths - Aondowase Boh, PhD

years and in recent times have looked at the family unit as being a substantial force in the fight against crime and criminality in the society. It is on this note that the paper takes a critical look at Tracie Utoh's The Night of a Thousand Truths in relation to the role of parents in enforcing a crime free society.

\section{The Synopsis of The Night of a Thousand Truths}

Tracie Utoh treats the issues of crime and crime management using a nuclear family that is made up of Daddy, Mummy and their children Tony, Candy, Mac and Andy. In the play, Daddy is a business man that is after money with total neglect of his family matters. Mummy, the mother is also after money and does not care about what happens to her children. As far as the play is concerned the parents do not take the future of their children seriously. They do not have quality time together for their children.

The lack of parental guidance and supervision make Tony to get himself entangled in armed robbery cases. He is arrested on several occasions by the law enforcement officers but the father in person of Daddy use his wealth and connections to bribe him out. The attitude of Tony's parents makes him to become a hardened criminal. Tony gets himself involved in an armed robbery operation where he kills the owner of a filling station and is caught and is executed. The execution of Tony becomes the subject of lamentation and discussion in the family as each member of the family accuse one another of being responsible for his execution or refusing to do the right thing to save him. Both parents are vehemently accused by Candy for not doing what is expected of them as responsible parents should to their children. This clearly shows that, when 
parents fail in their parental duties of socializing their children properly the children will grow up to indulge in criminal activities in the society.

The inability of Tony's parents to caution and discipline him paves way for his criminal life and his subsequent arrest and execution. Tony's execution therefore triggers off the reexamination of parents' roles as it affects the live of family members and society at large.

\section{Criminal Issues and Crime Management in the Play}

The play opens with Mummy, Tony's mother lamenting his death.

Mummy: My son oh oh. My son oh oh. My son oh oh. They have killed my son. They have killed my little boy...(79)

Tony is executed because of his involvement in armed robbery operation. Tony's death pains his parents particularly the mother to an extent that she refuse to be consoled by Daddy when she retorts:

Mummy: How can you ask me to bear this hurt? This burning pain that is tearing my inside apart. Can I ever bear it? Can I ever erase the memory of my poor boy being tortured and murdered. Oh! my son, my son

All attempts to console her prove abortive. This clearly shows that when parents do not train their children in the best possible way they will regret at the end.

Tony's execution would have been averted if the parents did something to caution him when he was going astray. Instead the parents from time to time use their wealth and connections to set Tony free whenever he was involved in an unlawful act. 
The Dramatist and Crime Management for National Stability: An Analysis of Tracie Utoh's The Night of a Thousand Truths - Aondowase Boh, PhD

Even the last straw that broke the camel's back, the parents tried all they could to set him free. They refused to look at Tony's involvement from an objective perspective. According to Mummy, Tony was framed and implicated in the robbery case. As far as mummy is concerned Daddy wants Tony to be killed even though Daddy tried all he could to set him free.

Daddy: It is not possible and you know it. Operation sweep is a special squad. The members are incorruptible. Yet I still struggle and tried to see if I could arrange a settlement through my extensive network of powerful associates ....Somebody somewhere was ready to play ball but they were asking for five million naira. Where on earth did you expect me to get such an amount from? (81-82).

This statement establishes clearly that, Tony's parents were in full support of his criminal activities. According to Mummy, if Daddy cared for their son, no matter the amount of money he would have raised it.

When Candy came back home, the story of Tony's criminal activities are laid bare for the parents to see how they have both contributed in making a criminal out of Tony. To Candy their parents have not faced the reality but have continue to live in falsehood which is responsible for Tony's death. She accuses the parents of been responsible to their (the children) wayward behaviour as the parents thought something has come over her. It is at this point that Candy puts it straight to them;

Candy: Nothing has come over me daddy I am more aware of my surrounding than you can ever imagine. I now have a vivid perception of reality. The reality of home. The decay, the 
pretence, the double standard, the hypocrisy, the cover-ups and above all, the lies. Lies everywhere. We are living in, the world of lies... (84).

From Candy's statement, it is clear that their parents are not doing what is expected of them. This informs why Tony becomes a hardened criminal that ends up being executed. Candy categorically informed her parents that, they are responsible for Tony's death and not the police. Her reaction to her mother's statement is a pointer to this fact.

Mummy: (resume fresh sobbing). My poor little boy. They have killed my innocent son. They have killed him. My son who had never harmed anybody in his life .They just killed $\operatorname{him}(86)$.

Candy: You know what he did Mummy. But you choose to live in a world of illusions. A world of falsehood. Unfortunately execution is real. Death is real. Tony is dead and you, not the police killed him (87).

This is a clarion call on parents to be mindful of what their children do in life and what they do to them. It means parents must be curious to know about the way and manner their children behave and the activities they indulge in. Candy informs us of this fact when she reminds her parents that:

Candy: The fact that you made Tony what he is today, I am not saying it was a preconceived act. Your actions might have been unconscious or even out of genuine concern. But it traverses a gradual route. The cumulative reality is that Tony becomes a master. The hardened criminal that was executed. (88) 
The Dramatist and Crime Management for National Stability: An Analysis of Tracie Utoh's The Night of a Thousand Truths - Aondowase Boh, PhD

The playwright insists through Candy that parents must have the future of their children at heart. It is well known that, the future of Nigeria as a nation and her citizenry is in the hands of Nigerian children. To this end children must be trained to imbibe these values that will benefit their future and that of the nation. Candy is right when she directs her parents attention to their duties.

Candy: You are our parents. Surely you have visions. So, what vision do you have for the future generation? ....The day you ask yourselves what you can do, so that another of your children does not end up as a social outcast, that day will mark the beginning of a new era, a new dawn, a new awareness, a new hope for the generations yet unborn. (91-92)

Just as the saying goes, if you can't beat them you join them, parents in Nigeria as represented in the drama find it difficult to admit their fault but rather elude their actions to the general happenings in the society. Thus Daddy is quick to remind us that, it is the system that is bad and they as parents are only dancing to the dictates of the society. It is in line with this that, he responds to Candy thus:

Daddy: You heap all the blame on our door step. Do not blame us. Blame the system. Ours is a system which thrives on the survival instincts of jungle dwellers. (92)

The playwright is saying that, parents should look through the future of their children and inculcate good moral values in them, in order to make the society a better place to live in. This view is projected in Candy's world view on parental obligations when she debunks the views of her father who thinks it is good to follow what others in the society are doing: 
Candy: Society is made of individuals. Not the other way round. The demise of the individual starts from the home. If the whole society is corrupt, you as parents can go contrary to conventional acceptability.... you know the difference between right and wrong. Impact that knowledge to your children. (92-93)

This is a clear indication that the way and manner children are brought up by their parents is paramount to what the children will end up doing when they become adults. Parents have a lot of responsibilities in bringing up their children; however many parents do not take this all important aspect of live serious. Many parents are the brain behind the bad behaviour and acts that their children exhibit in the society. This is presented in Candy's response to the supposed care and love Mummy presumed to show to her and her siblings.

Candy: Of course you do. Like when I was fourteen years old and Mummy encouraged me to be nice to a man who bought presents for her and became your business partner. Wasn't that for my own good? When I was pregnant at the age of fifteen and mummy took me for an abortion wasn't that for my good too? (89)

The playwright is canvassing for good moral orientation which is the basis of societal peace and harmony. This point is made through Candy when she advices her parents and parenthood in general in those words:

Candy: The point I am trying to make is this. Give your children good moral orientation when they come in contact with others the impact will effect positive change. (94)

This to some extent calls for self evaluation, self examination, self purgation, self reformation. The need to prod and probe 
The Dramatist and Crime Management for National Stability: An Analysis of Tracie Utoh's The Night of a Thousand Truths - Aondowase Boh, PhD

into the conscience, to ascertain the role of parents in ensuring a safe, harmonious society that is free of criminality.

Part of parents' responsibility to their children is to love, provide food, education, shelter, medication and general wellbeing. The situation whereby parents become more aware of their public image and business at the detriment of what their children do and what happens to them can lead such into a life of crime. The playwright clearly point out this through Candy's speech.

Candy: That is it! your public image! Impressions! That is all you care about. You do not care about us. How we feel. Our needs, our dreams, our desires, our hopes and aspirations. You do not care. You sacrifice our future on the alter of selfish ambitions. (95)

The playwright is saying that, for a peaceful society, parents should take their parenting job more seriously. Parents should have love between them. They should as well keep a close watch over their children. But if on the contrary parents do not love themselves, and are more interested in material things, their children will go astray, the result of which will be their involvement in criminal activities like armed robbery, cultism, which will lead to their untimely death as it is in portrayed in the person of Tony.

The parents in the play are not good example for the family unit. Their character is clearly seen in their arguments. Daddy for instance accuses mummy of being a flirt.

Daddy: You are the cause of all this, instead of you to train your children, you are running all over the place. Jumping from one man to another. (106) 
Mummy agrees with this but said she does this to help her husband secure his contracts. She in turn informs us about the character of her husband thus:

Mummy:...you are worst than a misfit. You are not just content with keeping hoards of girlfriends, you have two children outside marriage ...you buy stolen goods from criminals don't you? Why will your children not become criminals? You sell hard drugs. Definitely you expect to have consumers. If your son is one of them what different does it make?...To you money is everything. You worship money. Even to the detriment of your home. You do not spend time with your family, jetting from one country to the other...tell me can money replace a father's love and care? (107)

Utoh clearly asserts in the play that a family that is beset with conflict and crises cannot make way for a crime free society. It is a known fact that children of poor parents that are beset by economic difficulties and of wealthy parents whose extreme focus on social and career concerns leads them to nurture their children irregularly may be vulnerable to crime. There is therefore a call on families to be united with a focus of bringing up children that will be free from a life of crime. It is stated clearly that for peace, development and a crime free society, parents must be ready to love themselves. This love can be extended to the children who will in the long run impact on their future life. Apparently, children that grow up in a disrupted family are strongly associated with antisocial behaviours of which crime is among. It is this realization that the playwright concludes the play with a call on the family unit to be united so as to make progress and development. 


\section{Mummy: Yes. Together we shall embark on this journey...come sweetheart...come children...let us embrace the dawn of a new era. A rebirth. A resurgence. Our lives are bound together. We are a family, we are one.}

Indeed, if the entire nation as a family thinks in this manner most of the problems facing the nation will be overcome. This therefore calls for Nigerian families as a whole to unite and fight for the ideal nation where issues of crime and criminality will be done away with.

\section{Conclusion}

The role of the dramatist is to suggest possible ways by which crime can be reduced in the society. The Night of the Thousand Truths is therefore an issue based drama that projects family conditions that can lead people or family members into committing crime in the society. It is therefore the duty of would be audience or readers of the play to avoid those actions that can lead the society into crime for the reduction of crime and criminality in the society. The onus therefore rest on each member of the society to do what he or she can to reduce crime to the minimal level if not totally do away with it.

Tracie Utoh has clearly captured in the play that, the issue of crime and crime management is the collective responsibility of both parents to live in harmony with each other and take full responsibility of bringing up their children. To effectively do this, parents must be ready to collectively discipline, supervise and be responsible to what ever their children do in life. Even though in reality there are no guaranteed methods for ensuring that parents and their children will be happy, healthy and free 
from life of crime, however parents can make significant, positive difference through a number of approaches. Parents must not entangle themselves in acts of criminality so as to effectively supervise their children from the live of crime and criminality. Just like other playwrights, Utoh has used her play as a medium for societal reconstruction. She has clearly shown how parents' attitudes and behaviours have rather shaped and promoted the act of criminality in the society instead of reducing it. Acts of criminality are projected in the Night of a Thousand Truths with the aim of initiating self evaluation among Nigerian families, with a view to accelerating both human and material development. This dream of a crime free Nigeria is possible only if Nigerian families live up to their responsibilities of being responsible to their parenting duties.

\section{Works Cited}

Achebe, Chinua. The Trouble with Nigeria. Enugu: Forth Dimension, 1983. Print

Christensen, Charles K. and Joan E. Feinberg. The Bedford Introduction to Drama. New York: St. Martin's Press, 1989. Print.

Sanford, Nevitt. Self and Society: Social Change and Individual Development. New York: Atherton press, 1966. Print.

Utoh, Tracie Chima. The Night of a Thousand Truths. Jos:

Swiz Option Publication, 1999. Print.

Utoh-Ezeajugh, Tracie and Nneka Ibeli. "Dramatic Parables as Catalyst for Good Governance in Nigeria: A Paradigmatic Appraisal of A Parliament of Vultures, Hopes of the Living Dead and Morountodun." The Humanities and Good governance. Ed. Chiegboka A. B. C. et al. Awka: Rex Charles and Patrick Ltd, (2012): 318-327. Print. 
The Dramatist and Crime Management for National Stability: An Analysis of Tracie Utoh's The Night of a Thousand Truths - Aondowase Boh, PhD

Uya, Mary Erdoo. "Relationship between Hard Drug Use and Violent Crimes among Youths in Nigeria." Benue Journal of Sociology. Ed. Tseayo, Justine I. et al. 4.1 (2012): 103-116. Print.

http://www.mastersdegreeonline.org/resources/criminologyonline-an-in-depth-look-at-the-various-crimetheories 13-5-2013 